\title{
Suplemento al \\ Diccionario de Peruanismos
}

\author{
por Juan de Árona
}

\author{
I N T RODUCCION
}

Juan de Arona (Pedro Paz Soldán Y Unánue, 1839-1895) es un producto típico del romanticismo, y como tal lo alienta una profunda inquietud universalista. En su obra late la afición por el humanismo antiguo en su aproximación a los clásicos, a quienes traduce con fervorosa dedicación a lo largo de toda su vida. De ello son nuestras preclaras, sus libros Poesía latina, (Lima, Imp. J. F. Solís, 1883), en que recoge sus versiones de Lucrecio, Virgilio, Ovidio y Plauto, y anteriormente Geórgicas de Virgilio (Lima, Imp. "El Comercio", 1867). Esa formación humanística la adquieren durante su fructífera estada en Europa y especialmente mediante sus estudios en La Sorbona de París. Pero de allí también surgió el humanista moderno, patente en su culto por los grandes poetas modernos europeos, ingleses, alemanes, franceses e itálicos. En mis investigaciones sobre autores germanos e ingleses en el Perú he asentado el valor, el volumen y la calidad de su labor de traductor exquisito $\mathrm{y}$ apuntaré en próximos estudios otras muestras de su vocación por esa labor humilde, sacrificada y desdeñada que es la traducción literaria, en que hay la renuncia a toda soberbia de autor único y la generosa entrega de la contribución a la fama ajena. Gracias a él, en parte, se conocieron en el Perú a Pope y Byron, James Thomson, tanto como Goethe, Schiller, Freiligrath y a otros poetas europeos, cuyas versiones son tan encomiables.

Hay varias facetas - apartadas la de poeta, comediógrafo y satírico- un tanto preteridas en el estudio de la personalidad de Juan de Arona, que estamos empeñados en esclarecer. Son ellas $\alpha$ ) su trayectoria como viajero por el Perú y por el mundo, b) su labor de huma- 
nista $\mathrm{y}$ traductor insigne $\mathrm{y}$ c) su tarea de lingüista, que en realidad constituye la infraestructura, la piedra angular de su extraordinaria vocación creadora.

Arona fué un romántico integral, como lo fué en șu esencia el romanticismo. Debe recordarse siempre que este movimiento no solamente constituyó una "escuela" literaria, sino toda una nueva y distinta concepción del mundo y de la cultura, que se manifiesta en varias direcciones. El romanticismo tendió a nutrirse de temas tomados de las literaturas primitivas, de la creación popular auténtica y espontánea, en expansión temporal. Surgió de allí la investigación del "folklore", de las literaturas populares antiguas, del habla y costumbres del pueblo. El campo de la investigación científica se amplió en estos terrenos antes desconocidos de la antigüedad o del pueblo contemporáneo, y surgieron como ciencias de nuevo impulso la lingüística, la filología, el folklore, la antropología, la etnología. De otro lado, en su afán también universalista de expansión espacial, los escritores románticos se hicieron viajeros insignes por tierras lejanas y desconocidas del globo y trazaron los más bellos e intensos relatos de viaje que se hayan escrito alguna vez. El siglo XIX está preñado de este afán de traducir -que responde al llamado de conocer la literatura extraña, escrita en otra lengua- y de ese impulso de viajar escribiendo impresiones. Y al lado prospera también una inquietud febril, que induce a adentrarse en el alma popular $y$ en los paisajes $y$ usos propios de los pueblos con tradiciones y leyendas anónimas y peregrinas, en donde se abreva la inspiración de baladas y canciones:

Este romanticismo integral late intensamente en Juan de Arona, alma permeable a todos los estímulos de la cultura. Así surge el viajero-con una obra casi desconocida de impresiones por Europa y Oriente, que anda dispersa en diversos periódicos- y así se forma el traductor de clásicos y modemos. Igualmente, domina a lo largo de sus mejores años, su inquietud por el lenguaje nativo, por la parla del pueblo peruano y va gestándose de tal suerte, una obra perdurable que será su Diccionario de peruanismos.

Juan de Arona concibió por primera vez la idea de escribir un Diccionario de voces de su pueblo, estando en Londres en 1860. Hasta ese momento sólo conocía como antecedente directo de su proyecto el Diccionario de provincialismos de la isla de Cuba, de Esteban Pichardo, cuya segunda edición había aparecido en La Habana en 1849. MuY posteriormente alcanza a conocer otro intento similar que es el de Arístides Rojas que extracta de su Diccionario de vocablos indígenas de Venezuela, un pequeño folleto que contiene Cien vocablos indígenas 
de Venezuela, editado en 1882, en Caracas. En lo demás, contando a Rufino José Cuervo en Colombia, Juan de Arona llegó a ser uno de los más caracterizados pioneros de este tipo de investigaciones americanistas. La amplitud de su empeño y la vastedad de su cultura, hace que su llamado Diccionario de peruanismos tenga plena vigencia americana por sus observaciones válidas para todo el ámbito continental y por sus concordancias atinadas a los usos de los vocablos en distintos países del Nuevo Mundo y diversas localidades de España.

Su cultura lingüística y filológica se había nutrido de las enseñanzas de filólogos y humanistas recibidas en Francia y de sus lecturas de especialistas alemanes que por primera vez fueron asimiladas por un investigador latino-americano. Son frecuentes sus citas de Federico Diez, autor de Etimologisches Wörterbuch der romanischen Sprachen, de Die Deutsche Sprache, de Schleicher y de Altspanische Sprichwörter aus den Zeiten von Cervantes de Joseph Haller, entre muchas otras obras de significativos especialistas de la filología alemana que consulta con extraña familiaridad en escritores de América y España de esa época. A partir de 1860, y durante 35 años hasta su muerte en 1895, Arona dedica lo mejor de su tiempo en hacer realidad lenta y progresivamente $\alpha$ su trascendental proyecto. Todo lo restante de su producción intelectual parece subordinado a este empeño culminante de su obra. Acaso sus poesías -única faceta que ha merecido un relativo estudio de sus comentaristas - inficcionadas de cerebralismo y de afón descriptivo exagerado, y en que resulta dominante la idea de que el "sabor local" se logra por la frecuencia del tema y el motiyo nacional, no sean sino mero pretexto para dar libertad a su empeño de recoger" voces populares, dichos pueblerinos, denominaciones de cosas vemáculas, animales y plantas propias de este continente. En fatigante proceso, sus poemas registran hasta la saciedad y la insistente manía, miles de localismos que él se afana en incorporar a la creación literaria. Sus versos se resienten de una escasa inspiración de forma o de idea poética en medio de una dispersión y fragmentarismo de tópicos a lo largo de toda su obra de poeta. Las composiciones de Ruinas y de Cuadros y episodios peruanos y aún los casi inéditos Chispazos y las Rimas del Rímac adolecen de esos defectos literarios, pero constituyen caudal invalorable para esa labor compiladora de expresiones locales que da cima en su Diccionario, que es la obra sustancial de toda una vida.

Desde la aparición de Galería de novedades filológicas : vocabulario de peruanismos aparecido en Londres en 1861, se advierte la prosecución de su labor en el vocabulario anexo a sus Cuadros y episodios peruanos, de 1867, y luego en sucesivos artículos con partes de su 
Diccionario en progreso aparecidos en "El Correo del Perú", entre 1871 y 1872, en que llega a publicar el texto explicativo de 216 voces. Seguidamente, entre 1882 y 1884, publica la edición definitiva del Diccionario en Buenos Aires y Lima, adicionado de un primer suplemento que agrega a cada letra y confeccionado seguramente en el lapso de la publicación por entregas.

Pero no quedó allí su empeño de investigador, como se había creído hasta ahora. Ha dejado como se ha de ver, un segundo suplemento que llegó a publicar en los últimos años de su vida azarosa y ensombrecida por la desgracia material, en su periódico "El Chispazo", en medio de los sarcasmos y saetazos de su sátira impenitente contra la prosaica realidad social y política de ese momento, entre 1891 y 1893. Tal Suplemento ve la luz ahora en primera edición orgánica y superando la obligada fragmentación de las entregas aparecidas en efímero semanario, cuyas colecciones completas son escasísimas.

Pero Arona no se limitó a reunir únicamente vocablos y a consignar sus significados. Su obra realizó un plan de vasta envergadura, con respecto a la contribución linguística de América de habla hispana. Se propuso coleccionar vocablos derivados del quichua, o corrompidos del español, o inventadas por los criollos dentro del genio de la lengua castellana, o las mismas palabras castizas que aluden a objetos o costumbres propios del país. Pero no solamente se trata de la obra de un "virtuoso". No solamente se limita a una labor investigatoria y compiladora. En el desenvolvimiento de su obra, glosa vocablo por vocablo, haciendo acopio de anécdotas, de citas literarias $\rho$ costumbristas en que las voces glosadas viven $\mathrm{Y}$ palpitan, en forma tal que sus definiciones arrojan de lado todo dogmatismo y se empapan de vida y de agudas observaciones de artista $\mathrm{y}$ de poeta, dando a su texto un aliento literario de carácter inconfundible por la agilidad de exposición, el matiz humorístico y la ingeniosa recopilación de antecedentes y consecuentes. Allí mismo ejemplifica con su propia producción poética, tan nutrida de términos locales $y$ de significaciones de motivos $y$ objetos de su tierra y de realidades peruanas y americanas.

El Diccionario de Peruanismos ha resultado así una obra clásica de la literatura peruana por su contenido de investigación y por su caudal creador. Constituyó sin duda un acierto incluirlo entre las obras literarias representivas del Perú en la "Biblioteca de Cultura Peruana" de Ventura García Calderón, editada en París, en 1938.

No obstante el notable éxito de este libro y la difusión y calurosa acogida de la crítica que ha merecido posteriormente, no se ha reparado en que obra tan significativa y destacada había sido objeto de una am- 
pliación posterior a su publicación en 1883. Arona publica en casi todos los números de su periódico "El Chispazo" —que se edita de octubre de 1891 a junio de 1893 - un apéndice o suplemento que contiene otras voces no consignadas en la edición del libro. Sucesivamente, en 15 números de su revista, del $\mathrm{N}^{\circ} 1$ al $\mathrm{N}^{\circ}$ 66, publica Arona, desde la $A$ a la $Y$, una compilación posterior suplementaria, - con enmiendas, extensiones y agregados- que no se ha difundido y que andaba ignorada de las escasas colecciones que se conservan de ese periódico. Por eso el Instituto de Literatura de la Facultad de Letras de la Universidad Nacional Mayor de San Marcos, inicia su primera serie de publicaciones con el Suplemento al Diccionario de Peruanismos en que se recoge toda esa labor adicional casi desconocida y no incorporada a la posteterior edición del Diccionario que se hizo en 1938, pese a que constituye parte integrante e imprescindible del mismo.

Esta contribución ha de ser utilísima para los estudiosos de la lingüistica y filología americana y cubre en parte una faceta un tanto preterida de la producción del gran escritor peruano.

Pedro Paz Soldán y Unánue tomó su seudónimo del nombre de la Hacienda San Juan de Arona en que había trascurrido su infancia y adolescencia, en el valle de Cañete. Más tarde, perdido el patrimonio paterno, adoptó también el seudónimo "Juan sin tierra". En los comienzos de su vida estuvo material y espiritualmente vinculado con la tierra fértil del valle, mientras nutría sus inquietudes intelectuales juveniles en la Bibliotecả dē Hipólito Unánue, su abuelo Hace médula en su espíritu el culto de los poetas bucólicos a quienes traduce más tarde, y de las excelencias virgilianas, que ya habian caracterizado los últimos años del abuelo Unónue en sus escritos "Mi retiro" y "La vuelta a la vida del campo". Aunque desposeído materialmente de esa tierra, no dejó nunca Juan de Arona de estar íntimamente vinculado a la tierra peruana total que él amó tanto, en compensación de la pérdida de la heredad propia. Y esa aproximación a la tierra que nutre toda su obra, pervive en él a lo largo de los años y ha de producir ese fruto sabroso y espiritualmente nutritivo de recuerdos y estímulos peruanistas, de vivencias auténticas y de singular mensaje nacional y americano que constituyen las fichas de su imprescindible Diccionario.

Estuardo Núñez. 
SUPLEMENTO

A

ABARROTES : Cierto género de comercio, en artículos comestibles, equivalente a lo que en Madrid se llama Almacén de Ultramarinos. Abarrote es palabra española; mas no en el sentido que aquí se le da. México nos acompaña en el provincialismo, según se ve en este pasaje de Arroniz en su "Manual del Viajero en México" : "El comerciante va hablando del precio corriente de los abarrotes".

ABOCASTRO : Corrupción de avucastro, que es la palabra castiza, como que viene de avucasta (avutarda), o simplemente de ave con la terminación despectiva, como pajarraco de pájaro.

ACAPITE : Pórrafo. A lo que hemos dicho en el Diccionario, que no es poco, agregaremos que en el italiano se usa punto e a capo en el mismo sentido que por acá punto acápite. Una prueba más de que el presente no es un provincialismo indígena.

\section{Aculirico, Biblioteca de Letras}

ACULLICAR : Voces enteramente quichuas, de grandísimo uso en la Sierra y de gratísimo sentido para el indio habitador de estas regiones, puesto que con ellas se designa el apresto de su frugal alimentación indígena, tan frugal, que es uno de esos desayunos que los franceses llaman sur le pouce.

Acullicar es aderezar la yerba coca para llevársela a la boca, tomándola de la bolsa especial en que se guarda, y de un matecito, la punta de cal con que se sazona la hierba.

El acullico, es el bodoque que se forma dentro de la boca, y que el indio va gustando por media hora o cuarenta minutos, hasta renoviarlo con otro.

Viene acullicar del verbo quichua aculli, mascar hojas de coca y acullico de acullicu, donde apenas ha habido que cerrar la $u$. Esta pobre lengua parece que nació para armonizar con la española, cosa de que ni remotamente podrán jactarse ni la lengua de los Aztecas, ni la de los Araucanos, ni la de los Chibchas, ni ninguna otra americana, más o menos ásperas y salvajes. 
En el artículo Lampa y otros del Diccionario, hemos disertado sobre esta graciosa rotundidad y fácil eufonización de la antigua lengua peruana.

ADECUA : Con este indicativo e imperativo del verbo adecuar sucede lo que con todos los equivalentes de los verbos paliar, retaliar $y$ otros, que muchos preguntan : ¿Es pália o palía? Es retália o retalía?

El uso es vario. No asi en adécua, en donde lo general es y debe ser adecúa.

Mas nosotros velando siempre por la mayor riqueza del verso o de la rima pediríamos adécua, acaso como el único consonante a Congreso, digo, a recua.

$Y$ nos acompaña una excelente autoridad, la del ingenio español y clásico hablista, D. Tomás de Iriarte :

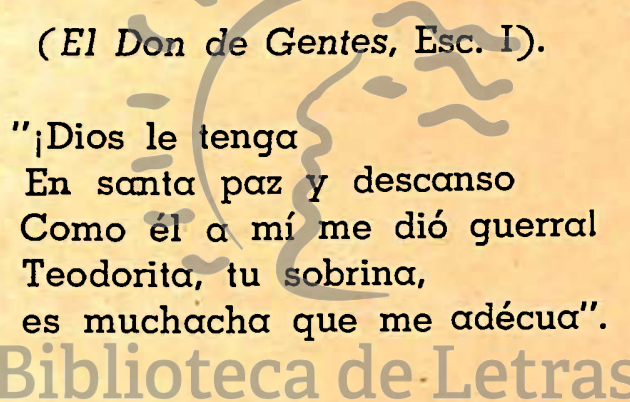

ADJUNTAR : Naturalísimo derivado de adjunto y de gran uso en el estilo oficial; aunque en nada mejora al clásico acompaño; pero no está en el Diccicnario. (1).

ADUEÑARSE : De grandísimo uso; adueñarse de una cosa, de una vo. luntad; mas como el anterior, no se encuentra en el Diccionario.

AFRICANA : O paloma africana. Especie de madrugadora, más fina, y a la que creo, importada. Es ave de jaula, y de un canto desabrido y friolento. En Buenos Aires la venden con el nombre de Torcaza francesa.- Véase Cuculí en el Diccionario de Peruanismos.

AGREDIR : Verbo inventado sobre el sustantivo agresión, y naturalmente defectivo, pues no habría nadie que soportara agreda, agrede, etc. A lo sumo se usa en el participio, agredido, y en el pretérito, agredió: fuera del infinitivo. En el Diccionario no hay rastros de agredir. 
AJI : Anda mucho tiempo en los Diccionarios de la lengua, adoptado; y al extenso párrafo que le hemos dedicado en el de Peruanismos, agregaremos el siguiente :

En Estados Unidos y en Andalucía lo llaman pimiento chile, o simplemente chile. Bartlett en su Dict. of Americanisms, y Fernán Caballero en algunas de sus novelas traen graciosos ejemplos de los efectos producidos por esta punjente especie en los paladares extranjeros.

Dice el segundo ("Un Servilón Y un Liberalito") "O por pimiento chile para untar los bordes de mi alcarraza, como hizo ayer, de manera que me abracé los labios".

$Y$ el primero (traducimos) : "Chile colorado (Español), Pimienta roja. En California, Tejas y en los Estados que confinan con Méjico, el término español corre universalmente. Se usa en forma líquida y en grandes cantidades". Y agrega Bartlett este ejemplo tomado de las Memorias del General Sherman : - "Se me sirvió un plato de conejo, con lo que yo zreí ver una abundante salsa de tomate. Al tomar un buen bocado, sentí como si se me hubiese metido fuego líquido. El tomate era Chile colorado".

ALICUYADO : En Huaraz llaman así a los que nosotros decimos papujos por la semejanza de la cara abultada por los lados, con la del cuy o conejo. El cuy es el cochinillo (conejillo?) de Indias de los europeos.

\section{"Jorge Puccinelli Converso"}

ALTAR : En la introducción al Diccionario de Peruanismos, y en varios de sus artículos no hemos dejado de clamar contra el empobrecimiento que el idioma sufre entre nosotros, a causa de no usarse sino los términos generales.

He aquí por qué llamamos uniformemente altar, a lo que el más inculto español denominaría retablo; palabra ignorada entre nosotros, aunque la cosa es bastante general.

Véanse los altares empotrados en la pared, a manera de alhacena o armario, en algunas de nuestras calles, como en la del Sauce., en el rincón de la Plazuela de Santo Tomás, y otros varios aquí y en los pueblos, que.son simplemente retablos y no altares.

En su origen esta voz significaba cuadro en tabla, siendo asimismo voz de la arquitectura.

Hay pues propiedad, como que los retablos que dejamos indicados son como unos cuadros figurados a mano dentro de la pared. 
AMATERIARSE : Llenarse de materia o pus una herida leve, como sucede inmediamente a las personas de mala encarnadura.

AMBARINA : Una de esas flores del antiguo Lima que, sin saber por qué, desaparecen y van a refugiarse en los monasterios, únicos lugares donde hoy se las encuentra, piadosamente cultivadas por las manos de las monjas, en esas macetas de barro cocido del antiguo Lima, que por tener la forma de botijuelas, había que enterrarlas, por no ser posible sentarlas en el suelo por su puntiaguda base.

Si el que se anticúen las voces es vergonzoso para el espíritu humano, según decía Voltaire, ¿no lo será mucho más el que pasen de moda las flores, especialmente si son simpáticas y olorosas?

La ambarina como la dalia y otras flores, fue introducida de Méjico a Lima, a mediados del siglo pasado.

ANCHETA : Como exclamación frecuente y familiar iqué ancheta! no la trae el Diccionario, lo que no impide que nos sea común este provincialismo con Andalucía, a juzgar por el siguiente ejemplo de Fernán Caballero, Un Verano en Bornos.- "Da gracias a Dios de verte libre de la tal Fanchetta; que no era mal ancheta".

ANCHOVETA : Especie del sardina más pequeña. Podría creerse que es un diminutivo de anchoa nombre español que designa un pescado, y que aqui conocemos por conserva y por salsas, si no estuviera más visible la etimología en anchoueta.

Con este nombre describe Thompson en el Glosario que acom. paña su "Alcedo, Geographical Dict. of América" un pez pequeño, pero muy sabroso que abunda en el lago de Chucuito, y que es una especie de cockerel.

$\mathrm{Y}$ el mismo Barcia en su Dicc. de la Lengua Española dice : "Anchoveta, pez pequeño y deliccdo, especie de boga que abunda en la laguna de Chucuito en el Perú".

Aunque el nombre nos venga de tan lejos, la cosa o sea la anchoveta, es propia de cualquiera de nuestras playas marítimas en la costa.

APA : Al apa. El Sr. Rodríguez considerc esta frase como chilenismo y cún le atribuye etimologías americanas. Pudiera ser; pero yo creería ver una corrupción de la voz española aupa, con que se 
alienta a los niños a que se alcen y del consiguiente verbo aupar, ayudar a subir, levantar, soliviar.

Simón Camacho, traduciendo una de las óperas bufas de Offenbach emplea el imperctivo aupa!

APACHURRAR : Corrupción de despachurrar, que nadie usa entre nosotros.

APENAR : Y apenarse. Verbo formado sobre el sustantivo pena. En español existe solamente el adjetivo apenado, lo demás es provincialismo.

ARAÑ : Nombre de la peseta boliviana en Puno, que recuerda el de perro y perro chico con que el pueblo español designa el centavo doble y el sencillo, dando el nombre de perro a cada uno de los leoncitos o leoncillos que figuran en el escudo nacional.

ARRAIZAR : Se dice del árbol recien plantado o planta tierna que está empezando a echar las primeras raíces. Es un verbo precioso. como que arraigar parece aludir a un acto posterior. Véase lechar en el Dicc. de Peruanismos.

ATRENZOS : Estar en atrenzos, estar en aprietos o en apuros. La locución parece de ló más español, y no se halla en el Diccionario. Sin embargo, un sacerdote de esa nacionalidad, el Padre Cappa en el ingeniosísimo juguetecómicol "Soluciones inesperadas". escrito para sus alumnos del colegio de San Pedro y representado por ellos, dice :

"Quiero alejar de tí males,

Quiero sacarte de atrenzos

Que si hoy sólo son comienzos,

Al fin comienzos fatales".

Lo que prueba, o que se usa en alguna parte de España o que el padre se había contagiado con nuestros provincialismos.

BACHICHE : Apodo que damos a los italianos, Según el malogrado escritor Perolari-Malmignati, es corrupción de Battista, por lo común que es este nombre entre los de esa nacionalidad.

Siendo así deberíamos decir Bachicha. 
BALANZA : Llamamos así al palo con que los funámbulos o volatines conservan el equilibrio en la cuerda. El nombre propio en español es balancín o contrapeso.

BANDEAR : A las diversas acepciones de este verbo, hemos agregado nosotros la acepción provincial de pasar a un individuo de banda a banda, de parte a parte, hiriéndolo.

Lo bandearon de un balazo.

BARCHILÓN : Medicastro, y más generalmente practicante o asistente de hospital. Este peruanismo es muy antiguo, puesto que lo hallamos usado aun en el Mercurio Peruano, que se publicaba en Lima, hace un siglo. "Sujeto hubo que perdió la herencia de su tío por las sandeces que en el juego le dijo, y un devoto barchilón purgó en un hospital la culpa de haberse comido una baraja". (Merc. Per. № 6, pág. 247).

BOCADO : Es "el veneno que se da a alguno en la comida para matarlo", hablando con propiedad. Nosotros aplicamos el nombre exclusivamente a la preparación que se confecciona para matar a los perros. En este caso los españoles dicen zarazas (femenino (plural).

BOLIVIANO : Es una majadería seguir usando este adjetivo con referencia a Bolívar. En los días que estaba reciente la fundación de Bolivia, se podía admitir que Constitución Boliviana significaba la Constitución dada por Bolívar. Hoy el nombre de la Repúbli$\mathrm{ca}$, como adjetivo, se sobrepone por completo al de su ilustre fundador. Y por Bibliografía Boliviana se entenderá, la relativa a Bolivia, publicada por don José Rosendo Guliérrez, y de ninguna manera la concerniente al Libertador que pudiera idear algún Larramendi.

En este caso podrá decirse Bolivarino.

BOMBA : Estar en bomba, estar borracho. En español nada de esto, pero se grita ibomba! para anunciar que viene un brindis, en las francachelas. Lo mismo en Méjico, Arroniz, Manual del Viajero en Méjico: "De repente suenan los gritos de lbomba!, ןbomba!, esto es, que se va a brindar por alguno".

BOTARATE : No es precisamente derrochador como pretendemos por acá, partiendo de la idea de botar su fortuna. Es más inocente 
su sentido en español, y entendemos que no pasa de badulaque. Fernán Caballero, Una en Otra : "Caballero, le dije : Es Ud. un insolente botarate, un atrevido mentecato".

"yrar -

BOTERO : En España, nada más que el que hace botas o cueros para vinos; entre nosotros, el que maneja el bote. A éste se le debe llamar batelero.

BRAZO : Aunque lo castizo es ir de bracero, también se encuentra entre los escritores españoles ir del brazo, como acá decimos Fernán Caballero. "Un servilón y un Liberalito"; "Un caballero llevando del brazo a una hermosa joven".

BREQUERO : El hombre que en los trenes manejan el breque (brete). En España, con mucha más propiedad se le llama guarda-frenos, $y$ por tanto se llama treno a lo que malamente nosotros, breque.

Åsí como el soldado es carne de cañón, el infeliz brequero es carne de tren, porque la más de las veces perece entre sus ruedas.

BUSCAS : Tener sus buscas y ser busquillo, son expresiones de las que no hay vestigio en el Diccionario de la Lengua, a no ser buscavidas.

Nosotros designamos con estas frases al hombre industrioso, diligente, dej recursos, etc.nelli Converso»

CACTUS : Desde que la palabra se ha castellanizado es cacto, no hay para qué seguir diciendo cactus, que entre otros inconvenientes, tiene el de no dar plural; salvo que forzadamente se dijera cáctuses.

CACHITO : (el).- Cubilete de suela mugrienta que se ve en el mostrador de todas las tabernas. Tiene siempre dentro unos cuantos dados, y sirve para echar a la suerte quién pagará el dilecto trago, cuando las pandillas entran a beber.

CALANDRIA : En otros puntos del Perú, que no son Lima, llaman así $\alpha$ un pájaro un poco menos grueso que un chirote, todo amarillo 
caña, salvo algunas manchas pardas por el lomo, y con el pico corto y muy grueso, Canta algo parecido al tordo de por acá y al chivio.

Aunque calandria es sinónimo de alondra, la nuestra nada tiene que ver con la de Europa, tan cantada por Goethe y demás poetas alemanes con el poético nombre de Larch, y por los poetas ingleses con el de larck.

Por acá se canta :

$\therefore$
"¿Qué importa que la calandria,
el ruiseñor y el jilguero,
canten para divertirme
si en mí no cabe consuelo?"

CAMARETA : No es español, sino diminutivo de cámara, y en las armas de fuego, la parte en que está la carga. Entre nosotros es pieza de gran significación en las fiestas de iglesia para hacer salvas, en los pueblos. Oigamos como la describía un viajero inglés, ahora más de 70 años:

"Picamos pues nuestras mulas, y poco después oímos la detonación de una camareta, que es un pequeño mortero, como de dos o tres pulgadas de diámetro y unas ocho de hondura, y a cuyo pie hay una chiminea. Tiene una asa y se parece mucho a un jarro grande. Después de cargada con pólvora se ataca con barro seco que se golpea con un mazo hasta dejarlo endurecido. Se pone entonces en el suelo con la boca para arriba, y se extiende una guía de pólvora; al dispararse, la detonación es igual a un cañón de ocho". - Stevenson, Twenty years residence in South America.

CANUTO : Provincialismo de Andalucía y nuestro; a pocos se les ocurrirá que el modo de decir correcto es cañuto, modo de hablar. que parece inherente de la plebe. Con frecuencica las voces castizas permanecen estancadas en el bajo pueblo, mientras por $\alpha$ rriba neologizan a su gusto.

CARANGANO : En la Sierra dan este nombre al piojo blanco.

CARAVANAS : Arracadas, pendientes de mujer, generalmente de perlas o brillantes. Esta palabra ha caído en desuso junto con la $\cos \alpha$. 
CASAMATA : Difícilmente habrá persona que no haga el plural casasmatas, creyendo que son unas casas que matan; mas todo hace creer con el alemán Federico Diez, que viene del griego Xasámata, que quiere decir foso.

COCADA : A las principales acepciones que hemos dado en el Diccionario, agregamos la de término itinerario, pues los indios de la Sierra significan con esta voz el trecho de camino que les dura en la boca una ración de hierba coca.

COMIBLE : Lo que es de comer; los españoles dicen comestible, que presenta el inconveniente de confundirse con el sustantivo, aún cuando sólo se usa en plural, comestibles.

"Al madurar la planta (la alcachofa) produce una flor turquí, que es la parte comible de la planta". - Alfaro y Larriva, Agricultura.

Los escritores científicos dicen edible y aún edulo.

COMIDA : Por pulpa y médula, al hablar de la comida de la fruta es impropio, a pesar de lo cual las voces propias, que son esas, únicamente figuran en los escritos científicos. El término familiar castizo es carne, que se usa poco, aunque solemos llamar carne de membrillo al machacado de esta fruta.

CONECTAR : Este groseroubarbarismo, oqueenooes más que el verbo inglés to connect, se generaliza más cada día en la conversación de la gente culta, refiriéndose a la conexión de los vapores del Pacífico con los del Atlántico. Lo natural es decir corresponde, o si a todo trance se quiere conservar la raíz, conexionar..

COMPETENTE : Es increíble lo que se abusa en Lima de esta palabra : itodo es competente! Se enumeran las cualidades de una mujer : competente; las excelencias de una comida: competente; lo largo de una distancia : competente; se habla de una paliza : competente. No es que la palabra esté mal empleada. sino que se abusa de ella. Por lo demás, no hay localidad ni pueblo que no haga otro tanto, sintetizando su pensamiento en tal o cual voz, que sirve de descanso a la pereza intelectual, que es la pereza más común en el género humano.

Los madrileños, por ejemplo, abusan atrozmente de la palabra atroz. 
CORTAPAPEL : En español, la plegadera, como se puede ver en cualquier libro de la Península, fuera del Diccionario mismo. Nuestros impresores usan este nombre; no siendo allí, nadie dice plegadera, sino cortapapel.

CRIOLLO : Todo lo que como hombre, animal, planta, fruta o flor, proviene o es originario de Europa o Africa, pero ha nacido en América; por eso aún a los negros se les solía llamar criollos, para distinguirlos de los bozales o venidos de Guinea.

En las haciendas de caña llaman criolla a una cañita tierna, de cañutos cortos, delgados, fina, enteramente gracilis, más propia para chuparla o regalarla que para molerla en trapiche o hacerla azúcar; como si el clima influyera en ella de la manera que en la limeña criolla, que es la 'mujer española, más diáfana, por decirlo así, más breve de cintura, mano y pie, más propia para el regalo que para el trabajo, y más impregnada de muliebritó, como dicen los italianos, palabra que podríamos traducir por sexualismo.

Tschudi en sus "Reisen" deriva a criollo, criolla del verbo criar, y no me parece mal, así como la poética palabra francesa nourrison, que denota alumno, educando, viene del verbo nourrir, nutrir, criar.

Littré coincide con esta etimología.

Criollo, criolla son hace siglos voces europeas; no así sus derivados acriollarse, acriollado, de uso exclusivamente provincial, Por excelencia o antonomasia se llama criollo a todo lo que está recargado de córacter indígena o local.

CUANDO! : Exclamación de refinada incredulidad, muy usada en lo familiar y que las mujeres suelen pronunciar muy sabrosamente.

Cuando yo era niño corría una canción o letrilla de circo con este estribillo, por lo que la llamaban El Cuando. El payaso la recitaba al público en las funciones de Maroma, recorriendo el circo con la mayor gracia mímica que podía.

Aún recuerdo que una de las coplas decía :

"Porque los que están amando usan de dos mil antojos,

Celos, malmodos, enojos;

pero darles plata

$\mathrm{Y}$ aquí venía la musiquita.

¡Cuando! 
CURTIEMBRE : Debe decirse curtiduría.

CUSPAR : Y el femenino la cuspa, de muchísimo uso en la agricultura. Equivalen a escardar y escarda.

Y cuspa, aporque y roce,

Más que su ocupación fueron su goce.

(Poesías Peruanas, 225)

\section{$\mathrm{CH}$}

CHABE : Planta rastrera que suele cuivir en invierno los cerros de Li$\mathrm{ma}, \mathrm{y}$ que sirve de pasto a los animales, esencialmente a las vacas que gustan mucho de ella. Ignoro la etimología y aún la ortografía de la palabrai no puedo decir si es con $b$ o con $v$.

CHANCAR : En Arequipa, moler, quebrantar, del quichua chamca, que significa eso mismo.

CHAPALEAR : Azotar el agua y por consiguiente-molestar a los circunstantes con las salpicaduras que resultan. El malogrado escritor argentino D. Juan Maria Gutiérrez opina que viene del araucano chapad, y también el autor del Diccionario de chilenismos, posterior al de peruanismos, da por principal esta voz. No veo para qué se vayachasta el araúcanolcuando en los diccionarios castellanos encontramos : "Chapalear : germanía, nadar". (Los españoles llaman germanía a la jerga de los gitanos, que es el argot de los franceses y el slang de los ingleses).

Hallamos también "Chapatal, lodazal o pantano".

"Chapatalear; dar golpes en el agua con los pies y las manos".

No es de creerse que una voz araucana fuera a penetrar hasta el fondo de la germanía o gitanería de España. Chapalear no es sino una variante de las formas antes mencionadas,

Véase Challar en el Dicc. de Peruanismos.

CHARQUECILLO : Pescado, seco, salado, de que se hace algún consumo en Arequipa. Lo llevan de la costa y es una especie de congrio, viniéndole sin duda el nombre provincial de haber pasado por un procedimiento análogo al charque de la Sierra, más la la saladura de que aquel carece.

Véase Charque en el Dicc. de Peruanismos. 
"El oficio de poeta
es muy ageno de tí,
¿Y cómo te atreves, dí
poeta de paporreta,
a hacer versos de a peseta,
cuanto a ciento por cuartillo
vendidos en baratillo,
es cosa que no se pasa?
Con tiempo pues a tu casa
vete a freir charquecillo".

Santiago Paz-Soldán

CHINA : Voz de muchísimo uso familiar en Perú, Chile, Colombia y quizás alguna otra repúblice hispano-americana. Sirve para designar o llamar a una criada cariñosamente, de más o menos estimałción.

El nombre está lejos de ser, como pudiera creerse, aún por el color de la que lo lleve, el femenino de chino, que es una de las denominaciones de castas que aquí tenemos, independientemente del chino asiático: es voz enteramente quichua, y significa en esa lengua, criada muchacha de servicio, y antes de eso, he'mbra de animales.

Sucede con esta voz lo que con malla, que es en quichua cualquier animal tierno omediano, y nuestro malton, maltona sólo se refieren al adolescente humano.

Véase Malton en el Dicc. de Peruanismos.

CHICHIQUEO : En Puno, el acto de lavar en una batea las arenas auríferas.

CHIRIMACHA : En la Sierra, cucaracha hedionda.

CHUCHO : El chucho llaman en la república Argentina al escalofrío de la terciana o al mero resfriado. Es voz nuestra, pues viene del quichua chuychu que significa mojado, hecho una sopa, y también el frío de la calentura.

CHUCHUY : Piojito imperceptible, peculiar a las gallinas y demás aves de corral en donde con frecuencia se hace una plaga. El plural debe ser chuchuyes, como el de amancae, amancayes, y el de pacae, pacayes. Lo advertimos porque es lo más corriente oir a- 
mancaes y pacaes, contra toda analogía española, lengua de la cual de ay sale ayes, de taray tarayes, de convoy convoyes etc.

CHUECO, CHUECA : El que tiene las piernas torcidas, patizambo, etc. En español sólo hay chueca, y no con estas acepciones, porque es el nombre de un hueso de la rodilla, y en diminutivo choquezuela.

\section{D}

DEFECCIONARSE : Con toda naturalidad hemos sacado este verbo provincial del sustantivo defección, y tiene mucho uso entre nosotros desde hace largos años. Véase este editorial del "Peruano" del 15 de febrero de 1843 : "Palpitaban aún los restos mortales de los rebeldes, con quien contaban los defeccionados del Sur".

DESDOROSO : Adjetivo naturalmente formado de desdoro, pero que no se halla en el Diccionario.

Ya hemos dicho que, por el Diccionario entendemos $\circ$ el de Salvá o el de Barcia, que representan un término medio entre la intransigencia académica y la barbarie de los demás Diccionarios, sin más excepción que el de Nemesio Fernández Cuesta.

DESEN'TENDENCIA: Se ènctentra en el Diccionario desentenderse, mas no el expresivo desentendencia, de tanto uso entre nosotros.

DIAFANO : Por su etimología griega y por el uso, no significa ni puede significar otra $\cos \alpha$ que líciaio, transparente, cristalino. $\mathrm{Er}_{3}$ el uso de acá es otra cosc, especialmente en el uso de las mujeres, que toman la palabra por menudo, frágil, y hasta por el gracilis de los latinos.

Nador más común que esta frase : "Qué carita tan diafanita".

DULCERIA : Así llamamos a lo que en España y aún en Buenos Aires llaman confitería. El Diccionario, empero, admite Dulcería como provincial.

E

ENTRABAR : Se diría que es el entraver de los franceses. En España no se dice sino trabar. 
ESCUPITAJO : Término despreciativo de escupir.

ESTAMPILLA : Para el Diccionario no es más que diminutivo de estampa, o bien otra cosa de que por acá no hay idea. Para nosotros, estampilla, es lo que los españoles llaman sello de correos, nombre que nadie usa en estas tierras.

$Y$ aquí como en aceitillo, mantequilla, jaboncillo, reivindicaremos para nosotros la propiedad y oportunidad, porque valen más esos nombres propios, que los circunloquios de aceite para el pelo, sello de correos, jabón de olor, y que la ambigüedad de manteca, que así es la gruesa del cerdo, como la fina de la vaca.

FALSETE : Para el Diccionario no es sino el término de música y algo más que no nos hace al caso; para nosotros es el diminutivo de hombre falso; y así se dice "es medio falsete"; "es muy falsete", etc.

FALTE O FARTE : Así llaman en Chile a lo que entre nosotros mercachifle.

FIELATURA : Nombre de una oficina de la Casa de Moneda. En el Diccionario no hay nadoede esto. únicamente Fielato, que es el cargo de fiel.

FIGUEROA : Nombre de una madera en el norte del Perú.

FILIPINA : Nombre de un juego de sociedad tan usado en Lima como en Europa, de donde nos ha sido traído, y que no hallamos descrito en el Diccionario.

La palabra no tiene nada que ver con las islas Filipinas; viene del alemán Vielliebchen, que se pronuncia Filibgien, de donde por corrupción ha salido Filipina.

Vielliebchen, literalmente quiere decir Muy queridita y equivale a un saludo cordial como el viditay de las arequipeñas.

Los yanquis dicen Fillipeen o Phillipina.

En Alemania, la persona que después de haber compartido la almendra doble, es sorprendida por la orra sin exclamar : ich denke, yo pienso, incurre en la pena de regalar unas frioleras, a las cuales se les llama Vielliebchens. 
FLOR DEL SOL : A muchas de las cosas de España o nuestras les damos un nombre propio, que no suele ser más que la traducción, explanación o descomposición de una frase, del nombre correcto consistente en una sola voz.

De pedernal sacamos piedra de candela, de lente, luna de aumento; y de girasol, flor de sol.

Otras veces preferimos el derivado directo, visible a los ojos de la cara, y decimos huertero en vez de hortelano, y sin causa conocida, leñatero por leñador, y adulón por adulador. Esto nos da dos lenguas : una vulgar y otra literaria.

Cuando hablamos usamos el provincialismo y cuando escribimos el término castizo. La flor del Sol es el girasol de los españoles. Su precioso nombre griego traduce el nuestro al pie de la letra : heliantho.

Góngora en uno de sus sonetos dice :

"Los más cariredondos girasoles imitará siguiéndoos mi albedrío".

\section{G}

GALLITOS DE PAPEL : En España los llaman pájaras.

GUAYANA : En àlgunas partes del Perúllaman así a la golondrina, que en Limg conocemos con el nombre de Santarrosita.

\section{$\mathrm{H}$}

HERIDOR : Dan este nombre en Buenos Aires a lo que aquí hechor. Ninguno de los dos términos satisface porque no dan idea completa del agresor.

\section{I}

IMBIBITO : Lo mismo que implícito. No hay vestigio en el Diccionario de este provincialismo, usado a roso y velloso por toda clase de gente.

Viene de embeber, y su relación más cercana es el término de farmacia imbibición. 
IMPAGO : El que no está pagado. No se halla en el Diccionario.

Ya hemos dicho que por el Diccionario de este Suplemento, entendemos el de Don Roque Barcia. Así como en el Diccionario de Peruanismos nos referimos al de Salvá.

\section{I}

LASTIMADURA : Esta palabra tan popular en nuestros labios, no se encuentra en el Diccionario. Con ella designamos una herida leve cualquiera, aún la que puede causarse con la punta de un alfiler.

LIMOSNERO : En el sentido de pordiosero, del que pide limosna para sí. Es un absurdo. Limosnero no es sino el que da limosnas o el que las recauda para aplicarlas a otros.

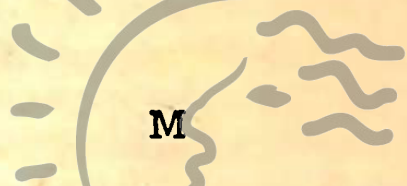

MANGUERA : Llamamos así a lo que los españoles manga de riego.

MANTA : La manta es la mitad del traje, por decirlo así, de la limeña, sea cual fuere su edad o condición, porque la trae puesta todo el tiempo que anda: en la calle a la iglesia, y sólo se presenta en talle $\circ$ en cuerpo, como por cácó sé dice, zuando, va de etiqueta.

Comporta, sin embargo, la manta grandísimo lujo y elegan. cia, porque las puede haber desde unos doce soles, llanas, hasta doscientos, recamadas o floreadas de magníficas labores chinescas, porque las mejores vienen de la China en sus cajas especiales, y son de vapor (espumilla).

Es el manto de las chilenas, salvo el lujo asiático de por acá, y la mantilla española, salvo la tela y el modo de llevarla. y finalmente, la manta de las cubanas, únicas que nos acompañan en el provincialismo.

Porque manta en castellano es sólo cobertor, frazada : "Mala la madre, mala la hija, mala la manta que las cobija". "Tiró el diablo de la manta y se descubrió el pastel", etc.

La orilla de lo manta está guarnecida por una cenefa de tul negro que cae sobre la cara, constituyendo casi un disfraz : al través de este encaje producen un lindo efecto los ojos y la boca, cuandc son como es debido, porque aquellos brillan como dos 
luces detrás de una rejilla y ésta como una cereza por entre una enramada.

El malogrado y brillante escritor italiano Perolari-Malmignatti en su libro "Il Perú e i suoi tremendi giorni" describe con toda minuciosidad y entusiasmo la manta limeña y el modo de llevarla.

MAPU! : Interjección caprichosa para designar el acto de echar mano a alguna cosa.

MARCHANTE : Aquí como en Andalucía equivale a parroquiano.

MASAMORRERO : Apodo de los limeños, limeño masamorrero, en los otros pueblos de la República, como el de Babazorros que dan los vizcaínos a los alaveses.

O se alude a una desmedida afición al plato nacional llama. do masamorra, afición que, a decir verdad, yo nunca he notado, o a un carácter blando como la masamorra.

Si es por esto último, Olmedo vindicó a los limeños desde los primeros años de la Independencia en los conocidos versos del Canto a Junín.

$$
\begin{aligned}
& \text { "¿Son éstos los garzones delicados } \\
& \text { entre sedas y aromas arrullados?" } \\
& \text { Biblioteca de Letras }
\end{aligned}
$$

MECHERO : Utensilio del fumador que sustituyó al yesquero después de la Independencia, en que abiertos al comercio universal nuestros puertos, hicieron irrupción entre nosotros los artefactos extranjeros.

Al canutillo lleno de yesca de nuestros padres sucedió la larga yesca pasada por un tubo de metal, hecho las más de las veces en el país mismo. de oro macizo y pesado y ostentando un lujo charro como el último recuerdo del rescate de Atahualpa.

La cadenilla que servía de regatón a la mecha, terminaba por una figurita tcimbién de oro macizo, que generalmente representaba a un indio con plumas. El menor precio de estas ricas piezas era de sesenta fuertes. Los mecheros populares importados mós tarde de Europa se componían de una mera hoja de latón con su mecha de lana colorada en toda su rusticidad.

En los mecheros ricos del país era de rigor que la mecha estuviese forrada en vistosa seda e impregnada de oloroso sahumerio que se despertase al prender aquella. 
Las monjas tenían la especialidad de aderezar estas mechas. Sencillos mecheros de delgada hojuela de oro, rle procedencia europea, no tardaron en desterrar a los anteriores. Hoy unos y otros han cedido a los fósforos, como la pintura a la fotografía, como el libro y el teatro al periódico, como la esgrima al revólver, como la biblioteca a la enciclopedia portátil, como todas las las complicaciones de marras a las simplificaciones modernas.

MOCONTULLO : La tierra de Mocontullo se suele llamar a Arequipa, sea refiriéndose al gran uso culinario del hueso llamado mocontullo en todas las cocinas de la ciudad del Misti, sea al mismo carácter sustancioso, fuerte y lleno de tuétano de los ribereños del Chili.

Del quichua tullu, hueso.

MOJARRA : El toro de la mojarra se llamaba en Lima en las corridas a la suerte o lance en que un pequeño grupo de cholos con una rodilla en tierra, recibía al toro en la punta de una pica o chuzo. El toro vencía la débil resistencia y pasaba de largo por encima de los cholos revolcados. Era como la suerte de la pica en España, pero a pie firme.

El mojarrero : el que hacía esto.

En Buenos Aires mojarra es el nombre de un pequeño pescado que se come fritoby mojcrrere es el de los trebejos con que se pesca.

La definición de mojarra en el Diccionario de la lengua dice : "Femenino: Pez marino ordinariamente pequeño y muy ancho".

MOSQUERO : Levantarse un mosquero es como levantarse un pulguero; sobrevenir gran cantidad de estos bichos en una habitación o casa.

Mosquero, en buen español, es un plumero para espantar las moscas, o los colgajos de papel que para recogerlas se ponen en los techos.

MUÑI-MUÑI : Papitas viles, menudas, que se suelen dar de yapa 0 adehala en los mercados. Ya hemos visto en otras voces por el estilo, que en quichua la repetición del mismo vocablo implica plural, serie, etc.

Así se ve en pata-pata, andenería; puchi-puchi, granadilla silvestre y rastrera. 
En Buenos Aires la misma palabra denota una planta medicinal de la Rioja.

\section{$\mathrm{N}$}

NARCOTIZAR : Este lindo verbo tan naturalmente derivado de narcótico, no se encuentra en el Diccionario. Ya le llegará su día. Es la historia de la mayor parte de los verbos derivados de sustantivos. Empiezan por chocar y después se generalizan. Ahora cien años los españoles se habrían escandalizado de oimos decir traicionar; en el día es verbo admitido.

A nosotros no se nos ha ocurrido todavía sacar verbo de viático, y en Madrid es lo más corriente viaticar, por administrar.

NOVIAZGO : Enteramente provincial, aunque muy gracioso. El estado de novio.

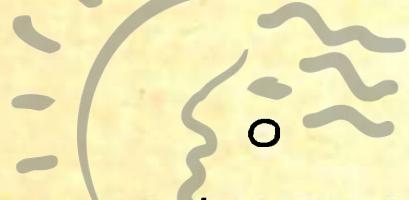

OBLAR : Lo mismo que narcotizar, no se encuentra ell el Diccionario, en donde sólo hallamos oblación.

\section{Biblioteca dp Letras

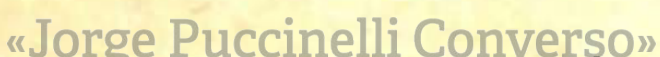

PACO : Enfermedad propia de los párvulos lactantes, especie de afta. Es voz quichua. En francés muguet.

PAÑOSO : El que tiene paños en la cara. Aunque este es el nombre en español de las manchas esas, pañoso no significa ya lo mismo en el Diccionario.

PAPUJO, JA : El que tiene la cara abultada u oblonga. Es voz de muchísimo uso.

PASTEAR : Estar pasteando a alguna persona; estar rastréandola, siguiéndole la pista, sin duda por la semejanza del pastor en el pasto, que no pierde de vista a la oveja.

PERJÚDICO, CA : Una variedad de perjudicial, que es lo único que trae el Diccionario. 
PICON, NA : El que se pica fócilmente de cualquier broma o alusión que se le hace.

PILOTIS : Los franceses dan este nombre, des pilotís, a las estacas so bre las cuales se construye en el agua. De pronto parece, come otras muchas voces extranjeras, que no tienen equivalente en español; sin embargo, se dice zampas, fem. plural.

PIZPIRILLA : Pizpireta.

PRECEPTUAR : Dar preceptos. Diremos lo que en narcotizar y en oblar: ya le llegará su día. Por lo pronto la Academia. en su Gramática, en un ejemplo, pone preceptuó, y también lo usa Dn. Antonic Valbuena que ha publicado varios tomitos titulados "Fe de erratas del Diccionario de la Academia".

Preceptuar no se encuentra en los Diccionarios a que nosotros nos referimos, que son el de Salvá y el de Don Roque Barcia.

PÚCHICAS : A Púchicas! Interjección vulgar, más o menos equivalente a ¡caramba! ¡cáspita!

PUNTAZO : Dar un puntazo. Herir con la punta de un estoque u otra arma análoga.

No se halla en el Diccionario.

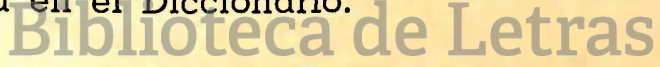

PRESCINDENCIA : Nō seoencuentråa en lèl Diccionario, y mucho menos Imprescindencia. Hay prescindir, prescindible, nada más.

Ténganlo Uds. presente, pero no se asusten más de lo preciso, no crean que porque usan una de estas voces, hijas genuinas del idioma, que tarde o temprano serán reconocidas, incurren en el pecado que con toda facilidad se enrostran aquí los ignorantes : "Eso no es castellano!"

\section{Q}

QUERENDON, NA : El o la que se engolosina demasiado en el querer. Son voces expresivas y de mucho uso.

QUINA : Antiguamente llamaban así las familias de Lima al juego de la lotería, con alguna impropiedad, porque la quina descrita por el Diccionario es un juego de dados enteramente distinto. Lotería es el nombre propio. 
QÜINGENTESIMO : El quingentésimo aniversario es una fiesta que en muchos siglos no podrán celebrar las jóvenes naciones de América. Para una vieja tradicional monarquía europea nada más fácil.

He aquí porqué el vocablo es tan natural y ocurre en un momento dado en Alemania, al conmemorarse un Jubileo como ellos llaman a sus fiestas conmemorativas de 500 años.

Este aniversario cinco veces secular se denomina en alemán fünfjahrhundert. ¿Cómo traduciremos al español este complejo y largo vocablo?

Un periódico español traduce el quinti anuario secular, tres palabras que, ni juntas, ni menos por partes, dan idea de la magnitud del aniversario.

¿Por qué no habilitan la palabra quingentésimo, muerta hoy en el fondo del Diccionario, no tanto por ser voz casi latina, cuanto porque en España nunca habrá habido ocasión de usarla de una manera viva como en Alemania?

En fünfjahrhundert, como en todas las voces compuestas del alemán, sólo hay composición como en las construcciones ciclópicas; fünt, jahr, hundert; en quingentésimo, los componentes han desaparecido a la vista y se han ido a refundir en el espíritu sintético de la lengua. Lo único que se puede rastrear es el fragmento del componente, pues lo es quin con respecto a quinque (cinco).

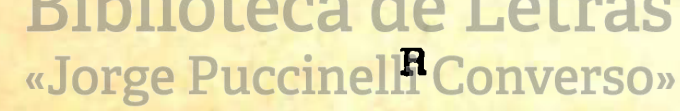

RASTRILLAR : Ninguna de las acepciones lexicográficas de este verbo corre aquí. Para nosotros sólo significa soltar el gatillo del arma de fuego. Y como la pieza en que éste hiere se llama en castellano el rastrillo, tal vez de allí hemos formado este verbo provincial.

Pues no creo que sea corrupción de rastrallar, con lo que se entiende en castellano chasquear el látigo o la honda.

Se puede rastrillar sin que salga el tiro, y casi siempre se entiende esto último.

El verbo se usaba mucho por acá en los días de las armas de fuego de pedernal.

REFACCIONAR : Reparar, restaurar una obra, y solamente el primer verbo y su sustantivo, reparación, debería usarse, porque si bien es verdad que el Diccionario admite refección en el sentido de re- 
paración, al verbo refaccionar no le da más significado que alimentar.

Así es que los cronistas de nuestros diarios no expresan nada cuando afectando un gran purismo, nos dicen: "que en tal calle se está refeccionando una casa".

SANDWICHS : Los famosos sandwichs de nuestros lunchs y saraos se llaman en Madrid emparedados. Deberíamos adoptar la palabra porque siquiera es española.

SAPA : De la mujer muy taimada, muy sabida, se dice que es muy sapa.

SENCILLO : Los españoles se escandalizan de oimos decir sencillo, por suelto, hablándose de la moneda. Y a los prisioneros chilenos que fueron a dar a Andalucía en los días de la cuestión española en el Pacífico, en 1864, cada yez que soltaban la palabra, les decían los andaluces con sorna: ¿Que quiere zarcillos? Los mismos españoles no sospechan que en muchos de nuestros provincialismos no hacemos otra cosa que estar hablando arcaísmos.

En "Don Quijote", primera parte, capítulo II, hallamos lo siguiente :

"Como haya muchas truchuelas, respondió Don Quijote, podrán servir de lunalrucha, porque eso me das que me den ocho reales en sengillos, que en und pieza de ocho":

SUCUMBE : Especie de punch o caspiroleta de que ya no se oye hablar.

SUERTERO : A lo dicho en el Diccionario sólo tenemos que agregar, que al suertero, que es uno de los más desgraciados nombres que hemos podido inventar por acá, lo llaman en Buenos Aires lotero, $y$ en Madrid billetero. Todo es menos absurdo que suertero.

TACHUELITA : Llamamos así a unos pequeñísimos clavitos, que los españoles denominan puntas de París, traduciendo directamente del nombre francés pointes de Paris.

TALLADOR : En el juego del monte el que lleva la baraja. Esto significa en español, entre otras acepciones, el verbo tallar pero ta- 
llador no se encuentra en el Diccionario, en la acepción que acá le damos a la palabra.

TARSANA : A lo dicho en el Diccionario acerca de esta corteza saponaria, agregamos aquí la etimología: Viene del quichua tacsana.

TEMPLADOR : Lo que en la plaza de toros de Madrid el burladero, se llama aquí el templador.

TERRAJEAR : Verbo de mucho uso entre nuestros albañiles y maestros, $y$ que no viene en el Diccionario.

TIMBUCHE : Tener timbuche o timbuches es tener sus complicidades, sus topujos, etc.

En los periódicos humorísticos de España, hallamos timbas en el sentido de tahures. ¿No será esta voz el origen de timbuches y timbirimbe?

TRAMITAR : rserbo de grondísimo y precioso uso en nuestros tribunales y que no hallamos en el Diccionario.

\section{$\mathbf{V}_{1}$}

VUELTO : El vuelto dedimosnosotros, loscéspañoles la vuelta, refiriéndose a lo que devuelvecel que vendererso"

\section{$\mathbf{Y}$}

YEGUARIZO : Por yeguada como aquí lo entendemos, es una monstruosidad. Yeguarizo, a estar en la analogía con porquerizo, cabrerizo, significaría a lo sumo el yegüero o guardión de yeguas, pero de ningún modo la manada de yeguas.

Campo en el éter de revueltos potros cuando huelen cercano el yeguarizo.

Así decíamos nosotros ahora muchísimos años.

YUCA : Extensamente hemos disertado sobre esta preciosa raíz en el Diccionario de Peruanismos.

Daremos aquí la etimología : Dice Gómara en su Historia de las Indias, que yuca es de la.lengua de Santo Domingo. 